\title{
Influence of Activation Time on Hemodynamic Parameters: a Simulation Study
}

\author{
Kosuke Taniguchi, ${ }^{*}$ Hiromasa Utaki, ${ }^{*}$ Daichi Yamamoto, ${ }^{*}$ Yukiko Himeno, ${ }^{*}$ Akira Amano,,
}

\begin{abstract}
Ventricular activation time (AT [ms]) is the time required to activate the ventricle electrically. The influences of AT on hemodynamics are of interest in clinical studies on methods for improving left ventricle (LV) function. However, the cardiovascular system is a dynamic system, in which many parameters are interrelated with each other, and teasing out the causality of the effects of AT within the system experimentally is difficult. In this research, we focused on analyzing the effects of changing AT on hemodynamics using a hemodynamic model by incorporating a cardiac tissue model into an LV geometric model within a circulation model. The cardiac tissue model is constructed by connecting 10 cardiac cellular contraction models in the fiber direction. In our cardiac tissue model, AT is represented by adding a constant delay time, $\delta_{\text {delay }}[\mathrm{ms}]$, to the starting times of calcium transients between adjacent contraction models. Thus, AT becomes $\delta_{\text {delay }} \times 9$ [ms]. Simulations were performed under two conditions: normal AT (99 [ms], physiological); and prolonged AT (207 [ms], pathological). AT prolongation caused slight decreases in stroke volume (SV $[\mathrm{mL}]$ ) and ejection fraction (EF [\%]) by $2.10 \%$ and $6.00 \%$, respectively, since both LV end-systolic and LV end-diastolic volumes increased by similar amounts. Maximum elastance $\left(E_{\max }[\mathrm{mmHg} / \mathrm{mL}]\right)$ decreased by $15.4 \%$. The maximum rate of LV pressure rise ( $\mathrm{max} \mathrm{dp} / \mathrm{dt}[\mathrm{mmHg} / \mathrm{ms}]$ ) decreased markedly by $43.7 \%$ at longer AT. The cellular mechanisms underlying changes in half sarcomere length were analyzed individually in 10 cells. Even though hemodynamic parameters did not change significantly, we concluded that large differences in cell behaviors existed.
\end{abstract}

Keywords: cardiac tissue model, activation time, hemodynamic parameters, cardiovascular simulation.

Adv Biomed Eng. 5: pp. 94-104, 2016.

\section{Introduction}

Animal experiments have long been used to study the mechanisms underlying heart pump function as well as the properties of cardiac cells and the cardiovascular system. Animal experiments provide helpful data to understand these mechanisms and properties, but since many interrelated factors act in the cardiovascular system, controlling for a single factor and distinguishing the direct results of that factor in animal experiments is difficult, which impedes advances in the understanding of the mechanisms underlying cardiac pump function.

For example, contraction of a cardiac cell is triggered by electrical excitation that propagates over the heart tissue, but the relationship between conduction velocity and pump function is not easily analyzed, since many factors are affected if conduction velocity is controlled. In the case of left bundle branch block (LBBB), cardiac function is reported to decrease [1-3], but distinguishing the effects of conduction delay from the effects of left and right ventricular asynchrony is difficult.

To complement animal experiments, simulations with a detailed cardiovascular system model may provide useful information. Computer simulations and analyses of simulation results are therefore gaining importance. Simulations of the heart are studied

This study was presented at the Symposium on Biomedical Engineering 2015, Okayama, September, 2015.

Received on August 2, 2015; revised on December 11, 2015 and February 26, 2016; accepted on March 23, 2016.

* Department of Life Sciences, Ritsumeikan University, Shiga, Japan

\# 1-1-1 Noji-higashi, Kusatsu, Shiga 525-8577, Japan.

E-mail:a-amano@fc.ritsumei.ac.jp at many levels, from cellular to organ level. The present research tried to analyze the basic mechanisms underlying cardiac pump function, which involves an excitation delay in cardiac tissue. We therefore identified the relationship between left ventricular (LV) activation time (AT [ms]; the time required for the entire LV wall to be activated) and heart pump function (evaluated from the following hemodynamic parameters: end-systolic LV volume $\left(V_{l v}\left(t_{E S}\right)[\mathrm{mL}]\right)$, end-diastolic LV volume $\left(V_{l v}\left(t_{E D}\right)[\mathrm{mL}]\right)$, stroke volume (SV $[\mathrm{mL}])$, ejection fraction (EF [\%]), maximum elastance $\left(E_{\max }[\mathrm{mmHg} / \mathrm{mL}]\right)$, maximum $\mathrm{LV}$ pressure (peak $p_{l v}$ $[\mathrm{mmHg}])$ and maximum rate of $\mathrm{LV}$ pressure rise $(\max \mathrm{dp} / \mathrm{dt}$ $[\mathrm{mmHg} / \mathrm{ms}])$ ); and analyzed the underlying mechanisms. Since AT is difficult to measure directly, QRS duration is often used as an index of AT. In the healthy human adults, QRS is reported to be under 100 [ms]. Murkofsky et al. [4] reported that prolonged QRS duration (>120 [ms]) correlates closely with decreased EF in patients. This finding indicates a strong relationship between prolongation of QRS duration and decrease of cardiac function.

As for simulation study, Lu et al. [5] reported a relationship between AT and isometric peak contraction stress using a cardiac tissue model. In their research, simulations were performed under conditions of constant tissue length, and the resulting peak stress decrease was around 3\% for an AT of 50 [ms] compared to an AT of 0 [ms]. However, the relationship between contraction stress and AT under physiological changes in cellular length remains unclear.

In this research, the relationship between pump function and AT was evaluated in order to analyze the basic mechanism, using a hemodynamic model by incorporating a cardiac tissue model into an LV geometric model within a circulation model. We used the hemodynamic parameters described above to evaluate pump function. 


\section{Model and Simulation Method}

\subsection{Model structure}

This research used a human hemodynamic model comprising a circulation model, an LV geometric model and a cardiac tissue model. The cardiac tissue model was constructed by connecting 10 or 50 cardiac cellular contraction models in the fiber direction.

\subsection{Circulation model}

A simplified circulation model as proposed by Heldt et al. [6] (Heldt model) was integrated into the hemodynamic model.

In our model, the LV compartment was replaced by the LV geometric model described in Section 2.3. To separate the effects of AT from other factors, the baroreflex model included in the Heldt model was removed. Cardiac cycle length was fixed at 1000 [ms]. In our combined model, we defined preload factor $K_{r p}$ ( $=2.43$ or otherwise stated in text) and used this factor to modify venous resistances as follows: $R_{\text {sup }}=K_{r p} \cdot R_{\text {sup } 0}, R_{\text {inf }}=K_{r p} \cdot R_{\text {info } 0}$ and $R_{a b}=K_{r p} \cdot R_{a b 0}$. Note that $R_{\text {sup } 0}, R_{i n f 0}$ and $R_{a b 0}$ are the original parameters of the Heldt model parameters.

\subsection{LV geometric model}

In the hemodynamic model, the following geometric model based on Laplace's law was used to relate LV pressure $\left(p_{l v}(t)[\mathrm{mmHg}]\right)$, radius $\left(R_{l v}(t)[\mathrm{cm}]\right)$, wall thickness $\left(h_{l v}(t)[\mathrm{mm}]\right)$ and wall stress $\left(F(t)\left[\mathrm{mN} / \mathrm{mm}^{2}\right]\right)[7]$.

$$
\frac{p_{l v}(t)}{h_{l v}(t)}=\frac{1.5 \cdot F(t)}{R_{l v}(t)}
$$

Since the primary variables in the hemodynamic model are LV pressure $\left(p_{l v}[\mathrm{mmHg}]\right)$, volume $\left(V_{l v}[\mathrm{~mL}]\right)$, half sarcomere length $(L[\mu \mathrm{m}])$ and wall stress $\left(F\left[\mathrm{mN} / \mathrm{mm}^{2}\right]\right)$, we have to provide the relationship between $\mathrm{LV}$ radius $\left(R_{l v}[\mathrm{~cm}]\right)$ and $V_{l v}$, between $R_{l v}$ and $L$, and between LV wall thickness $\left(h_{l v}[\mathrm{~mm}]\right)$ and $F$.

We used the following reported data to define mathematical equations for the relationship between $R_{l v}$ and $V_{l v}$. Corsi et al. [8] measured the time course of human LV volume, and Sutton et al. [9] measured the time course of human LV internal radius. Combining these data, we obtained a non-linear relationship between LV volume and internal radius. However, since the resolution of these data was insufficient, we used the time course of canine LV volume reported by Rodriguez et al. [10] and the time course of canine LV internal diameter reported by Sabbah et al. [11] to draw a non-linear relationship between LV volume and internal radius. When we linearly scaled end-systolic volume, end-diastolic volume, end-systolic internal diameter and end-diastolic internal diameter from canine data to human data as shown in Fig. 1, we obtained a curve with basic characteristics close to the human data. If we assume that the shape of the LV is close to hemispherical, the relationship between LV volume and internal radius becomes the following equation with $K_{\alpha}=3$.

$$
R_{l v}(t)=\left(\frac{V_{l v}(t)-V_{\gamma}}{K_{\beta}}\right)^{1 / K_{\alpha}}
$$

However, since the measured relationship shows disparity from the $K_{\alpha}=3$ curve, we optimized these parameters and obtained $K_{\alpha}=3.92\left(\mathrm{R}^{2}=0.95\right)$. Note that $V_{l v}(t)[\mathrm{mL}]$ denotes $\mathrm{LV}$ volume and the same as $V_{l v} . V_{\gamma}[\mathrm{mL}]$ is the $V_{l v}$-intercept of the relationship between $V_{l v}$ and $R_{l v}$. $K_{\alpha}$ and $K_{\beta}$ are model parameters that define the non-linear characteristics between $V_{l v}$ and $R_{l v}$.

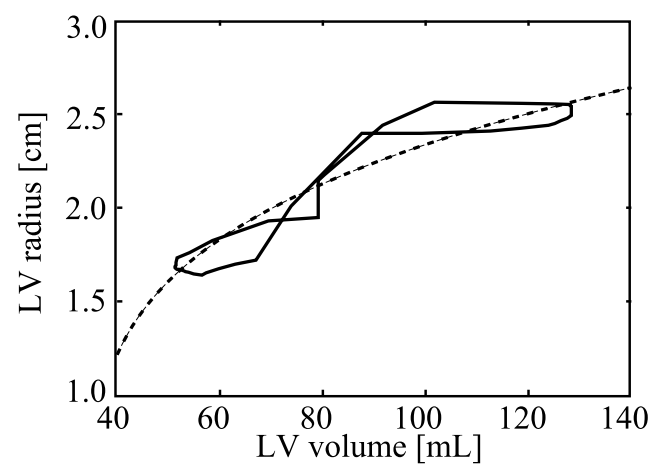

Fig. 1 Canine LV volume-radius relationship (solid line) and fitting curve (dashed line) scaled to human data.

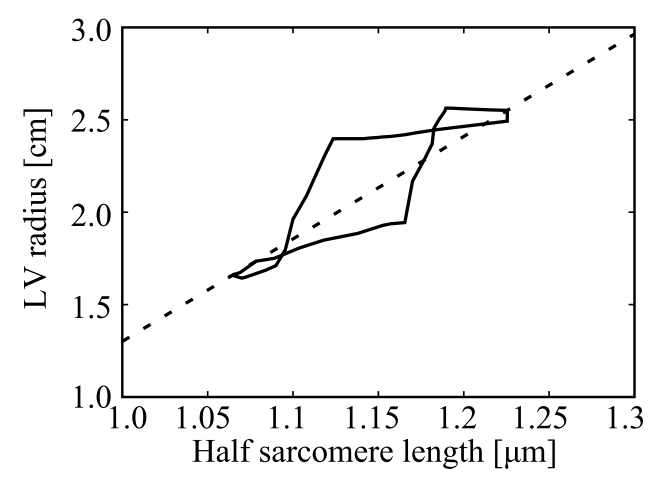

Fig. 2 Canine LV radius-half sarcomere length relationship (solid line) and fitting line (dashed line) scaled to human data.

We used the following reported data to define mathematical equations for the relationship between $R_{l v}$ and $L$. Rodriguez et al. [10] also measured the time course of canine sarcomere length. By combining this data with the measured canine time course of internal diameter as reported by Sabbah et al. [11], we obtained a non-linear relationship between LV volume and sarcomere length. We linearly scaled the working range of LV radius from canine (1.55-1.70 [cm]) to human $(1.643-2.56[\mathrm{~cm}])$, but not for half sarcomere length $(1.06-1.23[\mu \mathrm{m}])$, which is shown in Fig. 2, since the in vivo or in situ human sarcomere length has not, to the best of our knowledge, been reported.

$$
L(t)=C_{L} \cdot R_{l v}(t)+L_{b}
$$

$L(\mathrm{t})[\mu \mathrm{m}]$ denotes half sarcomere length and the same as $L$. $C_{L}[\mu \mathrm{m} / \mathrm{cm}]$ is the proportional constant of the relationship between $L$ and $R_{l v} . L_{b}[\mu \mathrm{m}]$ is the $L$-intercept of the relationship between $L$ and $R_{l v}$.

Next, we considered wall thickness. Yun et al. [12] measured the time course of LV volume, twist angle, and wall thickness, and reported that both volume and twist angle showed relationships with wall thickness. Moreover, wall thickness is known to become maximal at end-systole and minimal at end-diastole. However, wall thickness is not always proportional to LV volume [8,9], and the quantitative mechanisms underlying wall thickness remains unclear. On the other hand, wall thickness is known to change at isovolumic relaxation phase [13], where cellular contraction stress is decreased. We thus assumed that cellular contraction stress $\left(F_{b}(t)\left[\mathrm{mN} / \mathrm{mm}^{2}\right]\right)$ is linearly related to 
Table 1 Parameters in LV geometric model.

\begin{tabular}{ccccccccc}
\hline$V_{\gamma}[\mathrm{mL}]$ & $K_{\beta}$ & $K_{\alpha}$ & $C_{L}[\mu \mathrm{m} / \mathrm{cm}]$ & $L_{b}[\mu \mathrm{m}]$ & $F_{b}\left(t_{E D}\right)\left[\mathrm{mN} / \mathrm{mm}^{2}\right]$ & $F_{b}\left(t_{E S}\right)\left[\mathrm{mN} / \mathrm{mm}^{2}\right]$ & $h_{l v}\left(t_{E D}\right)[\mathrm{mm}]$ & $h_{l v}\left(t_{E S}\right)[\mathrm{mm}]$ \\
\hline 35.0 & 2.33 & 3.92 & 0.163 & 0.782 & 0.465 & 8.14 & 10 & 17 \\
\hline
\end{tabular}

$h_{l v}(t)$.

$h_{l v}(t)=\frac{F_{b}(t)-F_{b}\left(t_{E D}\right)}{F_{b}\left(t_{E S}\right)-F_{b}\left(t_{E D}\right)} \cdot\left(h_{l v}\left(t_{E S}\right)-h_{l v}\left(t_{E D}\right)\right)+h_{l v}\left(t_{E D}\right)$

Note that $h_{l v}\left(t_{E D}\right)[\mathrm{mm}]$ is end-diastolic LV wall thickness, $h_{l v}\left(t_{E S}\right)[\mathrm{mm}]$ is end-systolic LV wall thickness, $F_{b}\left(t_{E D}\right)[\mathrm{mN} /$ $\left.\mathrm{mm}^{2}\right]$ is end-diastolic cellular contraction stress, and $F_{b}\left(t_{E S}\right)[\mathrm{mN} /$ $\left.\mathrm{mm}^{2}\right]$ is end-systolic cellular contraction stress. Gerstenblith et al. [14] measured average age-specific cardiac wall thickness in human adults using echocardiography. We used their values for mean wall thickness. Parameter values of the LV geometric model are shown in Table 1.

\subsection{Cardiac cellular contraction model}

Models of cardiac contraction range from highly simplified models [15, 16] and empirical models [17] to biophysical models [18-20]. Since our aim was to analyze the mechanisms underlying the cardiac tissue with excitation delays, we used biophysical models. The Rice model [18] has a detailed biophysical representation of sarcomere structure and can reproduce both isotonic and isometric stress and length change, but the isotonic relaxation time course is rather slow, and the characteristics of instantaneous shortening and velocity-dependent stress decrease are not sufficiently realistic, given their importance in our model. The Land model [19] is one of the more sophisticated models, but is a mouse model with different characteristics from human cells. The stress-frequency relationships are also not physiological, which implies poor reproducibility with velocity-dependent stress decrease characteristics. On the other hand, the cardiac cellular contraction model proposed by Negroni and Lascano (NL08) [20] offers good reproducibility in isometric and isotonic contraction, and also at various transient length changes, based on the good reproducibility of velocity-dependent stress decrease characteristics. We thus used the NL08 model as the cardiac cellular contraction model in our hemodynamic model.

Cellular contraction stress $\left(F_{b}\left[\mathrm{mN} / \mathrm{mm}^{2}\right]\right)$ was calculated from the state transition model of the troponin system and mechanical model of the half sarcomere.

$$
\begin{aligned}
F_{b}= & A_{w} \cdot\left(\left[T S C a_{3}{ }^{\sim}\right]+\left[T S^{\sim}\right]\right) \cdot\left(L-X_{w}\right) \\
& +A_{p} \cdot\left(\left[T S C a_{3}{ }^{*}\right]+\left[T S^{*}\right]\right) \cdot\left(L-X_{p}\right)
\end{aligned}
$$

$A_{w}\left(=540\left[\mathrm{mN} / \mathrm{mm}^{2} / \mu \mathrm{m} / \mu \mathrm{M}\right]\right)$ and $A_{p}\left(=2700\left[\mathrm{mN} / \mathrm{mm}^{2} / \mu \mathrm{m} /\right.\right.$ $\mu \mathrm{M}])$ are constants to define the ratio of the contribution of crossbridges in weak (w) and power (p) states to generate $F_{b}$. [TSCa $\left.{ }^{\sim}\right]$ $[\mu \mathrm{M}],\left[T S^{\sim}\right][\mu \mathrm{M}],\left[T S C a_{3}{ }^{*}\right][\mu \mathrm{M}]$ and $\left[T S^{*}\right][\mu \mathrm{M}]$ represent concentrations of the troponin system forming crossbridges in the weak $(\sim)$ and power $(*)$ states. $\left(\left[\mathrm{TSCa}_{3}{ }^{*}\right]+\left[T S^{*}\right]\right)$ and $([T S-$ $\left.\left.\mathrm{Ca}_{3}{ }^{\sim}\right]+\left[T S^{\sim}\right]\right)$ are abbreviated as $T S_{p}[\mu \mathrm{M}]$ and $T S_{w}[\mu \mathrm{M}]$ in the text. $X[\mu \mathrm{m}]$ is the non-elastic portion of the contractile element and $\left(L-X_{w}\right)[\mu \mathrm{m}]$ and $\left(L-X_{p}\right)[\mu \mathrm{m}]$ are elongations of attached crossbridges in the weak and power states, $h_{w}[\mu \mathrm{m}]$ and $h_{p}[\mu \mathrm{m}]$, respectively. Note that $\left[\mathrm{TSCa}_{3}{ }^{\sim}\right],\left[\mathrm{TS}^{\sim}\right],\left[\mathrm{TSCa}_{3}{ }^{*}\right],\left[T S^{*}\right], h_{p}$ and $h_{w}$ are calculated by the equations in the original paper of the NL08 model [20] with modifications of $g$ and $g_{d}$ to be explained later.
Table 2 Parameters in Eq. (6).

\begin{tabular}{cccc}
\hline$K_{P E}\left[\mathrm{mN} / \mathrm{mm}^{2}\right]$ & $K_{P L}\left[\mathrm{mN} / \mathrm{mm}^{2}\right]$ & $D$ & $L_{0}[\mu \mathrm{m}]$ \\
\hline $5.871 \times 10^{-4}$ & 0.700 & 51.90 & 1.051 \\
\hline
\end{tabular}

Since characteristics of the end-diastolic pressure volume relationship (EDPVR) are similar in rats [21] and humans [22], by linearly scaling the stress axis with the identical half sarcomere length axis, we used the following mammalian exponential function as a human passive elastic stress $\left(F_{p}\left[\mathrm{mN} / \mathrm{mm}^{2}\right]\right)$ model showing good agreement with the experimental data [23, 24]. The format of this equation was based on the equation used by Shim et al. [25] and Landesberg et al. [26].

$$
F_{p}= \begin{cases}-K_{P L} \cdot\left(1-\frac{L}{L_{0}}\right) & L<L_{0} \\ K_{P E} \cdot\left(\mathrm{e}^{D\left(\frac{L}{L_{0}}-1\right)}-1\right) & \text { otherwise }\end{cases}
$$

Note that $L_{0}[\mu \mathrm{m}]$ is resting half sarcomere length. $D, K_{P L}[\mathrm{mN} /$ $\left.\mathrm{mm}^{2}\right]$ and $K_{P E}\left[\mathrm{mN} / \mathrm{mm}^{2}\right]$ are the scale parameters for the heart wall and cardiac cell passive elasticity. Parameter values were manually obtained to reproduce physiological human hemodynamics (Table 2).

Since $F_{p}$ is usually measured using a piece of tissue, we can consider that the characteristics of $F_{p}$ are compatible with the macroscopic properties. On the other hand, since $F_{b}$ is usually measured with a single cell or small piece of ventricular fiber in which the effective cross-sectional area is difficult to measure, measured stress may contain large scale errors. We thus introduced a scale factor, $K_{s}$, which is multiplied only to $F_{b}$ to adjust cellular contraction stress. $K_{s}$ was determined using the method proposed by Utaki et al. [27] which resulted in $K_{s}=6.65$. Finally, total muscle stress $F\left[\mathrm{mN} / \mathrm{mm}^{2}\right]$ as used in Eq. (1) as wall stress is calculated as follows.

$$
F=K_{s} \cdot F_{b}+F_{p}
$$

Stimulation time in the NL08 model is controlled by the $\mathrm{Ca}^{2+}$ release equation. The release and uptake of $\mathrm{Ca}^{2+}$ by the sarcoplasmic reticulum $\left(Q_{\text {rel }}[\mu \mathrm{M} / \mathrm{ms}]\right.$ and $\left.Q_{\text {pump }}[\mu \mathrm{M} / \mathrm{ms}]\right)$ in the NL08 model are expressed using the following equations.

$$
\begin{aligned}
& Q_{\text {rel }}=Q_{m} \cdot\left(t / t_{1}\right)^{4} \cdot \mathrm{e}^{4\left(1-t / t_{1}\right)}+Q_{\text {pump_rest }} \\
& Q_{\text {pump }}=K_{p} /\left(1+\left(K_{m} /\left[\mathrm{Ca}^{2+}\right]\right)^{2}\right)
\end{aligned}
$$

where $t[\mathrm{~ms}]$ is the time parameter, $\left[\mathrm{Ca}^{2+}\right][\mu \mathrm{M}]$ is the concentration of $\mathrm{Ca}^{2+}, Q_{m}[\mu \mathrm{M} / \mathrm{ms}]$ is the maximum level of $\mathrm{Ca}^{2+}$ release, $t_{1}[\mathrm{~ms}]$ is the interval to maximum $Q_{\text {rel }}, Q_{\text {pump_rest }}[\mu \mathrm{M} / \mathrm{ms}]$ is a parameter to determine $\left[\mathrm{Ca}^{2+}\right]$ at rest, $K_{p}[\mu \mathrm{M} / \mathrm{ms}]$ is maximum value of $Q_{\text {pump }}$ and $K_{m}[\mu \mathrm{M}]$ is the value of $\left[\mathrm{Ca}^{2+}\right]$ for $Q_{\text {pump }}=$ $K_{p} / 2$. Parameter values used in Eq. (8) and (9) are shown in Table 3.

The NL08 model is known to have a problem in the filling phase, where contraction stress rapidly decreases when half sarcomere length extends. To improve filling phase characteristics, we modified $\gamma$ in the crossbridge detachment rate parameters $g[1 / \mathrm{ms}]$ and $g_{d}[1 / \mathrm{ms}]$ in the NL08 model by introducing the 
Table 3 Parameters in Eq. (8) and (9).

\begin{tabular}{ccccc}
\hline $\begin{array}{c}Q_{m} \\
{[\mu \mathrm{M} / \mathrm{ms}]}\end{array}$ & $\begin{array}{c}t_{1} \\
{[\mathrm{~ms}]}\end{array}$ & $\begin{array}{c}Q_{\text {pump_rest }} \\
{[\mu \mathrm{M} / \mathrm{ms}]}\end{array}$ & $\begin{array}{c}K_{p} \\
{[\mu \mathrm{M} / \mathrm{ms}]}\end{array}$ & $\begin{array}{c}K_{m} \\
{[\mu \mathrm{M}]}\end{array}$ \\
\hline 3.2 & 8 & 0.03 & 0.15 & 0.2 \\
\hline
\end{tabular}

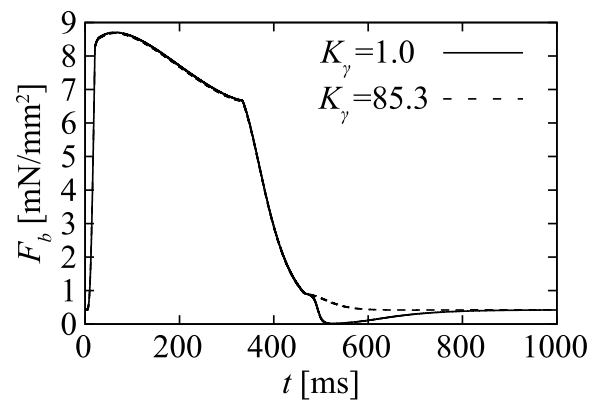

Fig. 3 Time courses of NL08 cellular contraction stress transient with $K_{\gamma}=1.0$ (original) and $K_{\gamma}=85.3$ (modified).

factor $K_{\gamma}$.

$$
\begin{aligned}
& g=Z_{a}+Y_{v} \cdot\left\{1-\mathrm{e}^{-\gamma_{m}}\left(h_{w}-h_{w r}\right)^{2}\right\} \\
& g_{d}=Y_{d}+Y_{c} \cdot\left(L-L_{c}\right)^{2}+Y_{v d} \cdot\left\{1-\mathrm{e}^{-\gamma_{m}}\left(h_{w}-h_{w r}\right)^{2}\right\}
\end{aligned}
$$

$h_{w r}[\mu \mathrm{m}]$ is steady elongation of attached crossbridges in the weak state. $Z_{a}[1 / \mathrm{ms}]$ and $Y_{d}[1 / \mathrm{ms}]$ are crossbridge dissociation constants, $Y_{v}[1 / \mathrm{ms}]$ and $Y_{v d}[1 / \mathrm{ms}]$ are model parameters for the weakly attached crossbridge elongation, and $Y_{c}\left[1 / \mathrm{ms} / \mu \mathrm{m}^{2}\right]$ and $L_{c}[\mu \mathrm{m}]$ are model parameters relating to the half sarcomere length. In the original NL08 model, $\gamma$ is used instead of $\gamma_{m}$ in Eqs. (10) and (11) which determines the positive nonlinear crossbridge detachment rate by the difference between $h_{w}$ and $h_{w r}$ that increases if $d L / d t$ becomes large. However, contraction stress becomes $0\left[\mathrm{mN} / \mathrm{mm}^{2}\right]$ after rapid elongation of $L$ (Fig. 3 solid line), which does not happen in the real heart, since if this happens, LV pressure becomes negative at this moment. We thus replaced $\gamma$ by $\gamma_{m}$ in Eqs. (10) and (11) which is identical to $\gamma$ if the cell is contracting; however, by dividing $\gamma$ by $K_{\gamma}$, the value becomes small, which gives better stress transient. By manually adjusting the smoothness of the stress time course, we used 85.3 as the value of $K_{\gamma}$ (Fig. 3 dashed line).

\subsection{Cardiac tissue model}

Since the heart can be decomposed into several long fiber bundles, we assumed that one fiber bundle surrounding the LV can be considered as a LV wall tissue model with an AT. We thus used a cardiac tissue model constructed by connecting 10 cardiac cellular contraction models in the fiber direction (10-cell model), which represents a fiber bundle surrounding the LV.

Here, the left-most cell in the tissue model is termed cell 1, and the right-most is cell 10. Half sarcomere length, cellular contraction stress, passive elastic stress, and total muscle stress of each cell are represented as $L_{1}-L_{10}[\mu \mathrm{m}], F_{b 1}-F_{b 10}\left[\mathrm{mN} / \mathrm{mm}^{2}\right]$, $F_{p 1}-F_{p 10}\left[\mathrm{mN} / \mathrm{mm}^{2}\right]$, and $F_{1}-F_{10}\left[\mathrm{mN} / \mathrm{mm}^{2}\right]$, respectively. Cellular contraction stress, passive elastic stress, total muscle stress, and average half sarcomere length of the tissue are represented as

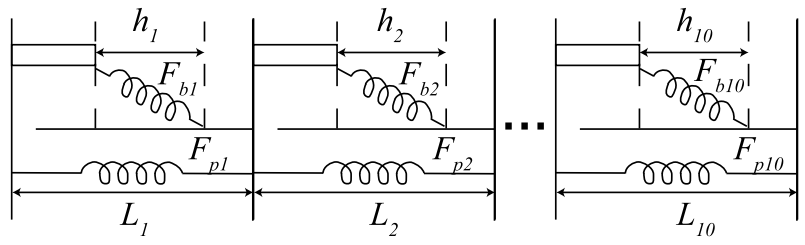

Fig. 4 Schematic of the cardiac tissue model. $h$ : crossbridge elongation, $L:$ half sarcomere length, $F_{b}:$ stress generated by crossbridge between thick filament and thin filament in half sarcomere and $F_{p}$ : stress generated by parallel elastic component.

$F_{b}\left[\mathrm{mN} / \mathrm{mm}^{2}\right], F_{p}\left[\mathrm{mN} / \mathrm{mm}^{2}\right], F\left[\mathrm{mN} / \mathrm{mm}^{2}\right]$, and $L_{\text {ave }}[\mu \mathrm{m}]$, respectively. Fig. 4 shows a schematic of the cardiac tissue model.

$L_{\text {ave }}$ can be expressed as follows.

$L_{\text {ave }}=\left(L_{1}+L_{2}+\cdots+L_{10}\right) / 10$

Since the serially connected cardiac cells have identical total stresses, the following equation holds.

$$
F=F_{1}=F_{2}=\cdots=F_{10}
$$

According to Eq. (13) and (14), the following system of equations can be derived.

$$
\left\{\begin{array}{c}
L_{a v e}-\left(L_{1}+L_{2}+\cdots+L_{10}\right) / 10=0 \\
F_{1}-F_{2}=K_{s} \cdot F_{b 1}+F_{p 1}-\left(K_{s} \cdot F_{b 2}+F_{p 2}\right)=0 \\
F_{2}-F_{3}=K_{s} \cdot F_{b 2}+F_{p 2}-\left(K_{s} \cdot F_{b 3}+F_{p 3}\right)=0 \\
\vdots \\
F_{9}-F_{10}=K_{s} \cdot F_{b 9}+F_{p 9}-\left(K_{s} \cdot F_{b 10}+F_{p 10}\right)=0
\end{array}\right.
$$

ATs can be altered by modifying the time parameter $t$ in the equation $Q_{\text {rel }}$ (Eq. (8)) by a constant time $\left(\delta_{\text {delay }}[\mathrm{ms}]\right)$. Equation $Q_{\text {rel }}$ in cell $i$ is described as follows.

$$
\begin{aligned}
Q_{\text {rel }}= & Q_{m} \cdot\left(\left(t-\delta_{\text {delay }} \cdot(i-1)\right) / t_{1}\right)^{4} \\
& \cdot \mathrm{e}^{4\left[1-\left(t-\delta_{\text {delay }} \cdot(i-1)\right) / t_{1}\right]}+Q_{\text {pump_rest }}
\end{aligned}
$$

Since there are 10 cells in the tissue model, the relationship between $\mathrm{AT}$ and $\delta_{\text {delay }}$ becomes the following.

$$
A T=\delta_{\text {delay }} \times 9
$$

As mentioned in Section 1, AT is closely related to QRS duration. QRS duration is under 100 [ms] in healthy human adult. On the other hand, under pathological conditions, QRS duration can be longer than 200 [ms] [28]. Here we assumed that LV AT is almost the same as QRS duration and defined two AT conditions by fixing $\delta_{\text {delay }}$ at $11[\mathrm{~ms}]$ and $23[\mathrm{~ms}]$ as follows: normal AT (n.AT) $(\mathrm{AT}=99[\mathrm{~ms}]$, a physiological condition) and prolonged AT (p.AT) (AT = 207 [ms], a pathological condition). The length of the average ventricular myocyte is around $100[\mu \mathrm{m}]$, corresponding to at least 1000 cells in a fiber bundle surrounding the LV. To evaluate the effect of the number of cardiac cells in the tissue model, simulation was performed using a cardiac tissue model comprising 50 cardiac cellular contraction models (50-cell model).

\subsection{Simulation method}

Simulations were performed with a simBio system [29] in 0.01ms steps until a steady state was reached, requiring around 100 cardiac cycles. In each step, the non-linear simultaneous equation was solved using the Newton-Raphson method.

\section{Simulations}

To evaluate the effect of the number of cardiac cells in the tissue 
Table 4 Hemodynamic parameters and parameters used to represent characteristics of the cell and cardiac cycle obtained at AT $=99[\mathrm{~ms}]$ (normal AT: n.AT) and 207 [ms] (prolonged AT: p.AT).

\begin{tabular}{c|c|c|c}
\hline & n.AT $(\mathrm{AT}=99[\mathrm{~ms}])$ & \multicolumn{2}{c}{ p.AT $(\mathrm{AT}=207[\mathrm{~ms}])$} \\
\hline$p_{l v}\left(t_{E S}\right)[\mathrm{mmHg}]$ & 112.3 & 111.1 & $-1.07 \%$ \\
\hline$p_{l v}\left(t_{E D}\right)[\mathrm{mmHg}]$ & 5.81 & 6.77 & $+16.5 \%$ \\
\hline$V_{l v}\left(t_{E S}\right)[\mathrm{mL}]$ & 47.5 & 54.0 & $+13.7 \%$ \\
\hline$V_{l v}\left(t_{E D}\right)[\mathrm{mL}]$ & 119 & 124 & $+4.20 \%$ \\
\hline$L\left(t_{E S}\right)[\mu \mathrm{m}]$ & 1.0323 & 1.0604 & $+2.72 \%$ \\
\hline$L\left(t_{E D}\right)[\mu \mathrm{m}]$ & 1.1886 & 1.1947 & $+0.513 \%$ \\
\hline $\mathrm{SV}[\mathrm{mL}]$ & 71.4 & 69.9 & $-2.10 \%$ \\
\hline $\mathrm{EF}[\%]$ & 60.0 & 56.4 & $-6.00 \%$ \\
\hline peak $p_{l v}[\mathrm{mmHg}]$ & 113.6 & 112.1 & $-1.32 \%$ \\
\hline max dp/dt $[\mathrm{mmHg} / \mathrm{ms}]$ & 6.18 & 3.48 & $-43.7 \%$ \\
\hline$E_{\text {max }}[\mathrm{mmHg} / \mathrm{mL}]$ & 3.58 & 3.03 & $-15.4 \%$ \\
\hline Duration of isovolumic contraction phase $[\mathrm{ms}]$ & 71.24 & 106.5 & $+49.5 \%$ \\
\hline Duration of ejection phase $[\mathrm{ms}]$ & 281.9 & 265.1 & $-5.96 \%$ \\
\hline Onset time of ejection phase $[\mathrm{ms}]$ & 80.6 & 115 & \\
\hline
\end{tabular}

model, we first performed a simulation with 10-cell and 50-cell models. The simulations were performed under identical conditions. The results showed that the maximum difference in $V_{l v}$ was less than $1.0 \%$, with no significant differences for the other parameters. On the other hand, computational time was 24 times greater for the 50-cell model than for the 10-cell model. We therefore used the 10-cell model in subsequent studies.

We performed simulation with two different ATs and observed the effects of AT prolongation on LV. Numerical values of hemodynamic parameters and parameters used to represent characteristics of the cell and cardiac cycle obtained from this simulation study are listed in Table 4. Time courses of $p_{l v}$ s for the two different ATs were superimposed on corresponding traces of aortic pressure $\left(p_{a}\right)$ and venous pressure $\left(p_{v}\right)$ in Fig. 5(a). We found that $p_{l v}\left(t_{E S}\right)$ and $p_{l v}\left(t_{E D}\right)$ changed by only $-1.2[\mathrm{mmHg}]$ and $+0.96[\mathrm{mmHg}]$, respectively. The smaller value of $p_{l v}\left(t_{E D}\right)$ compared to $p_{l v}\left(t_{E S}\right)$ made the apparent change seem as large as $+16.5 \%$. The time courses of $V_{l v}$ s for two different ATs are also plotted in Fig. 5(b). Both $V_{l v}\left(t_{E S}\right)$ and $V_{l v}\left(t_{E D}\right)$ were confirmed to increase when AT was prolonged. Since both $V_{l v}\left(t_{E S}\right)$ and $V_{l v}\left(t_{E D}\right)$ increased by similar amounts $(6.5[\mathrm{~mL}]$ and $5[\mathrm{~mL}]), \mathrm{SV}$ did not change markedly. However since $V_{l v}\left(t_{E D}\right)$ increased with AT prolongation, EF, which was calculated by dividing SV by $V_{l v}\left(t_{E D}\right)$, obviously became smaller. The difference in $V_{l v}\left(t_{E S}\right)$ was slightly larger compared to the difference in $V_{l v}\left(t_{E D}\right)$ for both ATs. The peak value of $p_{l v}$ was unchanged, whereas max dp/dt showed a large decrease after AT prolongation. Simulation results showed that the isovolumic contraction phase is markedly prolonged and onset time of ejection phases is delayed by AT prolongation, which is supposed to be the outcome of decreased $\mathrm{dp} / \mathrm{dt}$. The relationship between average LV pressure rise and max dp/dt will be analyzed in a later section. Conversely, duration of ejection phase was shortened by AT prolongation.

From the time courses of $p_{l v}$ and $V_{l v}$, we obtained the PV loops as shown in Fig. 5(c) that have similar properties to the reported human PV loop [30-32]. To evaluate $E_{\max }$ from PV loops, it was necessary to obtain values of $p_{l v}\left(t_{E S}\right)$ and $V_{l v}\left(t_{E S}\right)$ from at least 2 PV loops. Venous resistances were therefore modified by changing the value of preload factor $K_{r p}$ to 3.375 from 2.43 under two AT conditions. Lines were then drawn through the 2 points of $p_{l v}\left(t_{E S}\right)$ and $V_{l v}\left(t_{E S}\right)$ for each AT condition and are shown with PV loops in Fig. 5(c). The slope of the lines was defined as $E_{\max }$ and listed in Table 4. In clinical studies, $E_{\max }$ obtained from a few points of $p_{l v}\left(t_{E S}\right)$ and $V_{l v}\left(t_{E S}\right)$ is often used as a hemodynamic parameter, because it is almost impossible in human subjects to control venous resistances within a wide dynamic range of physiological conditions. In simulation studies, on the other hand, obtaining the relationship of $p_{l v}\left(t_{E S}\right)$ and $V_{l v}\left(t_{E S}\right)$ in a wide physiological dynamic range is feasible. As a result, we changed the value of $K_{r p}$ for the 0.675 to 4.86 range, in which $p_{l v}\left(t_{E S}\right)$ ranged from $90[\mathrm{mmHg}]$ to $130[\mathrm{mmHg}$, and drew the end-systolic pressure-volume relation (ESPVR) curves. The resulting ESPVRs are shown in Fig. 5(d). The slope of ESPVR was not always constant, meaning that $E_{\max }$ was not unique for each AT condition and depended on the loading condition of the hemodynamic model. The ranges of $E_{\max }$ calculated from the slope of two adjacent plot points for n.AT and p.AT [Fig. 5(d)] were 2.85-4.46 [mmHg/ $\mathrm{mL}]$ and $2.73-3.33[\mathrm{mmHg} / \mathrm{mL}]$, respectively. A larger variation of $E_{\max }$ in n.AT suggested higher non-linearity of n.AT compared to p.AT. These data showed clearly that as AT increased, $V_{l v}$ became larger. As a result, the $V_{l v}$-intercept of the ESPVRs, which was referred to as $V_{0}$ in previous research, increased as AT was prolonged.

Changes in $E_{\text {max }}$, max dp/dt, EF and SV at fixed $K_{r p}\left(K_{r p}=\right.$ 2.43 for max dp/dt, EF and SV; $K_{r p}=2.43$ and 3.375 for $E_{\text {max }}$ ) with varying AT are plotted in Fig. 6. These parameters depend on load conditions. Although $E_{\max }$ seemed to decrease slightly in relationship to AT increase in Fig. 6(a), the curvilinear characteristic of ESPVRs under different loading conditions in Fig. 5(d) should be taken into account. Decrease in max dp/dt was one of the most prominent effects of AT prolongation among all hemodynamic parameters. The reasons are discussed in Section 4.3. 


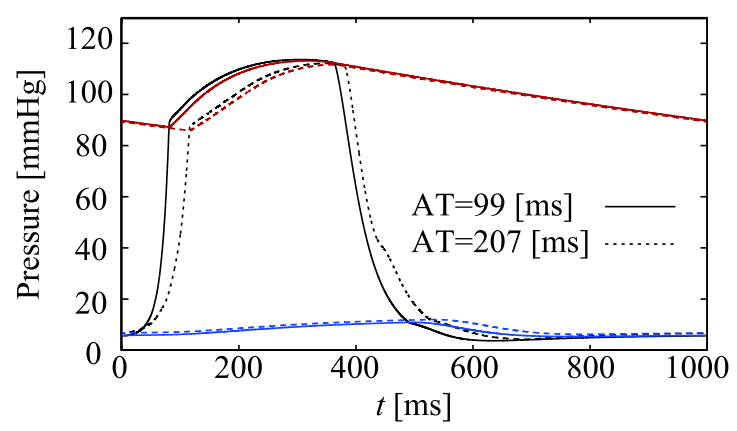

(a) Time courses of $p_{a}, p_{v}, p_{l v}$. The red lines show $p_{a}$. The blue lines show $p_{v}$. The black lines show $p_{l v}$

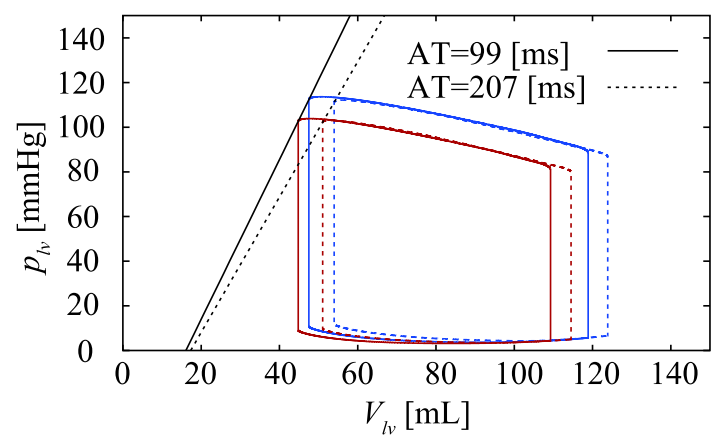

(c) PV loops. The blue lines show PV loops when $K_{r p}=2.43$ The red lines show PV loops when $K_{r p}=3.375$. The black lines show ESPVRs obtained from the two PV loops.

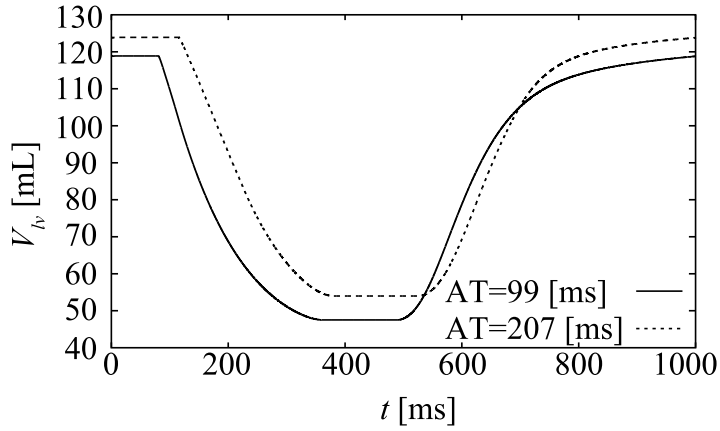

(b) Time courses of $V_{l v}$

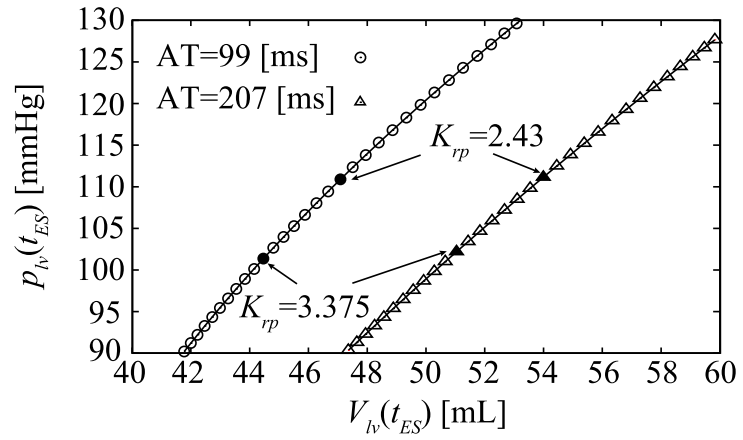

(d) ESPVRs

Fig. 5 Time courses of $p_{a}, p_{v}, p_{l v}$ and $V_{l v}$, PV loops and ESPVRs at different ATs.

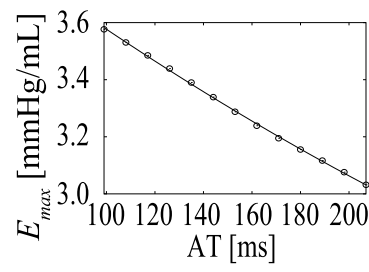

(a) $E_{\max }$ vs AT

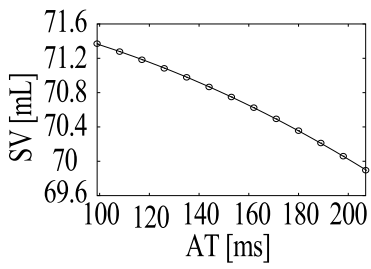

(c) SV vs AT

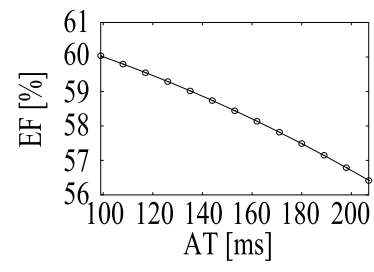

(b) EF vs AT

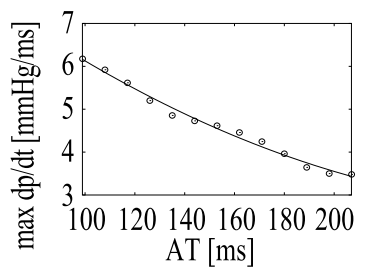

(d) $\max \mathrm{dp} / \mathrm{dt}$ vs $\mathrm{AT}$
Fig. $6 E_{\max }$, EF, SV and $\max \mathrm{dp} / \mathrm{dt}$ in relation to AT.

Decreases in values by changing AT from normal 99 [ms] to prolonged 207 [ms] were small for EF $(-6 \%)$ and almost negligible $(-2 \%)$ for SV. The decrease in EF was induced by the larger $V_{l v}\left(t_{E D}\right)$ at longer ATs.

Although we also compared EDPVRs for different ATs, no significant differences were identified.

\section{Discussion}

\subsection{Effects of AT prolongation on hemodynamic parameters} and cardiac cellular parameters

Simulation results revealed that although $\max \mathrm{dp} / \mathrm{dt}$ decreased markedly, $p_{l v} \mathrm{~s}$ at closure of valves on the aortic and venous sides, corresponding to $p_{l v}\left(t_{E S}\right)$ and $p_{l v}\left(t_{E D}\right)$, respectively, changed by merely $-1.2[\mathrm{mmHg}]$ and $0.96[\mathrm{mmHg}]$ when AT was prolonged. These changes in $p_{l v}\left(t_{E S}\right)$ and $p_{l v}\left(t_{E D}\right)$ were small, but indispensable for increasing $V_{l v}\left(t_{E S}\right)$ and $V_{l v}\left(t_{E D}\right)$ to a similar extent $(6.5[\mathrm{~mL}]$ and $5[\mathrm{~mL}]$, respectively), which, as a result, maintained SV after AT prolongation.

We observed increases in both $L_{\text {ave }}$ and $F_{b}\left(t_{E S}\right)$ at end-systole ( $L_{\text {ave }}\left(t_{E S}\right)[\mu \mathrm{m}]$ and $\left.F_{b}\left(t_{E S}\right)\left[\mathrm{mN} / \mathrm{mm}^{2}\right]\right)$ in response to increased cardiac load, induced by decreasing $K_{r p}$ (Fig. 7). We defined the relationship between $L_{\text {ave }}\left(t_{E S}\right)$ and $F_{b}\left(t_{E S}\right)$ as the end-systolic force-length relation (ESFLR). It should be noted that at end-systole, $F_{b}$ approximated $F$ because the effect of $F_{p}$ was negligibly small. The mechanisms for the positive shifts of ESPVR (Fig. 5(d)) and ESFLR (Fig. 7) to the right, i.e., expansion of $V_{l v}\left(t_{E S}\right)$ and elongation of $L_{a v e}\left(t_{E S}\right)$, after the prolongation of AT were not clarified in detail in this study. In ESFLR, the positive shift in $L_{\text {ave }}\left(t_{E S}\right)$ was always accompanied by an upward shift in $F_{b}\left(t_{E S}\right)$. Certainly, it is clear from the Laplace's law (Eq. (1)) that in order to produce an almost equivalent $p_{l v}\left(t_{E S}\right)$, an increase in $R_{l v}$, which is linear to $L$, should always accompany increases in $F_{b}$. Differences in curvilinear characteristics between ESPVR and ESFLR were attributable to the non-linear relationship between 


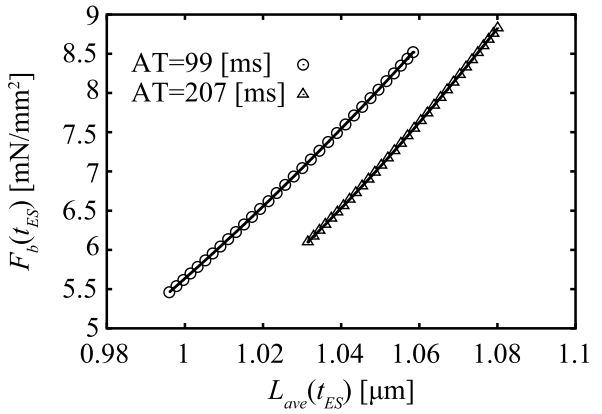

Fig. 7 Relationship between $L_{a v e}\left(t_{E S}\right)$ and $F_{b}\left(t_{E S}\right)$ (AT $=99$, $207[\mathrm{~ms}])$.

$V_{l v}$ and $R_{l v}$ as shown in Fig. 1.

\subsection{Variable responses of individual cells to AT change}

To obtain further insights into mechanisms underlying the effects of AT prolongation, behaviors of each cell in the cardiac tissue model were analyzed as shown in Figs. 8(AT $=99[\mathrm{~ms}])$ and 9 $(\mathrm{AT}=207[\mathrm{~ms}])$. In Figs. 8(a) and 9(a), $F_{b}$ of 10 cells $\left(F_{b 1}-F_{b 10}\right)$ are shown individually. Note that all $F_{\text {s }}$ were the same in 10 cells at all times. The onset of $F_{b}$ was delayed by magnitudes of $\delta_{\text {delay }}$ values $(=11[\mathrm{~ms}]$ or $23[\mathrm{~ms}])$ and time courses of the upstroke were delayed in the first few cells of total 10 compartments. The remaining cells subsequently showed increased $F_{b}$ and reached their peaks sequentially. When the last cell reached the peak $F_{b}$ in the middle of the ejection phase, $10 F_{b}$ s gradually converged and the time courses almost coincided. This phenomenon suggested that $F_{p}$ s were decreased in the process of cell shortening and almost completely disappeared at the time when all $F_{b}$ s converged. At end-systole where $p_{l v}$ balanced with $p_{a}$, the valve between aorta and LV was closed $(t=362[\mathrm{~ms}]$ and $380[\mathrm{~ms}])$. Relaxation of cardiac tissue then proceeded, as represented by a synchronous rapid drop in $F_{b}$ s. At the point where $p_{l v}$ balanced $p_{v}$, the valve between the vein and LV was open $(t=490[\mathrm{~ms}]$ and $526[\mathrm{~ms}])$. $F_{b}$ was small in the filling phase, and became almost comparable to $F_{p}$ at end-diastole, and was most effective at end-diastole when the tissue was maximally extended. The lengths of individual cells $\left(L_{1}-L_{10}\right)$ are shown with the average length $\left(L_{\text {ave }}\right)$ in Figs. 8(b) and 9(b). Cell 1 started to contract in response to $\mathrm{Ca}^{2+}$ signals without delay, which in turn extended the remaining cells at a resting $\mathrm{Ca}^{2+}$ concentration within the tissue model. We defined the period from the time when Cell 1 started to contract until the time when $L_{10}$ became shorter than the initial length as the early contraction phase $(0-177.1[\mathrm{~ms}]$ in Fig. 8, and 0-276.2 [ms] in Fig. 9). In the early contraction phase, Ls of the cells to be activated were extended to the maximum. During the isovolumic contraction phase $(9.370-80.61$ [ms] in Fig. 8, and 8.880-115.4 [ms] in Fig. 9), since $L_{\text {ave }}$ was unchanged, shortening of $L$ in cells contracted earlier was compensated by elongation of $L$ in cells contracted later. During the isovolumic relaxation phase (362.5-490.0 [ms] in Fig. 8, and 380.5-526.6 [ms] in Fig. 9), on the other hand, preceding elongation of the first few cells compensated for shortenings of $L$ in the remaining cells contracting later. To clarify why $F_{b}$ in all 10 cells gradually converged toward end-systole and synchronized despite large variations in $L$ during ejection and isovolumic relaxation phases, the concentra- tion of crossbridges in the power state $\left(T S_{p 1}-T S_{p 10}[\mu \mathrm{M}]\right)$ and crossbridge elongation in power state $\left(h_{p 1}-h_{p 10}[\mu \mathrm{m}]\right)$ for each cell are shown in Figs. 8(c), (d) and 9(c), (d). These parameters were used in calculating $F_{b}$ in Eq. (5). Note that parameters for crossbridges in the weak state in $F_{b}$ equation $\left(T S_{w 1}-T S_{w 10}[\mu \mathrm{M}]\right.$ and $\left.h_{w 1}-h_{w 10}[\mu \mathrm{m}]\right)$ for each cell are not shown because of their similar trends as $T S_{p 1}-T S_{p 10}$ and $h_{p 1}-h_{p 10}$ and have relatively small contributions to $F_{b}$. According to the equation which gives $h_{p}$ velocity in the original NL08 paper (Eq. (10) in [20]), $h_{p}$ is basically related to the first- and second-order derivatives of $L$. Thus, at the period when $L$ shortening is accelerating, $h_{p}$ becomes small, and vice versa. Since the changes of $L$ s in Fig. 8(b) and Fig. 9(b) have similar trends, the changes to $h_{p} \mathrm{~s}$ in Fig. 8(d) and Fig. 9(d) are basically similar. Initial slowing of the upstroke in $T S_{p}$ in cells activated earlier was the cause of the delayed upstroke of $F_{b} \mathrm{~s}$ in Figs. 8(a) and 9(a), and attributable to increases in detachment parameters, $g$ and $g_{d}$, calculated from Eqs. (10) and (11). During the relaxation phase, $T S_{p} \mathrm{~s}$ in the first few cells activated earlier were too low to generate cellular contraction stress. Therefore, those cells were extended and increased $h_{p}$ to balance the stresses generated by other cells. The characteristic increases in $L$ and $h_{p}$ of the few cells activated earlier during isovolumic relaxation phase were caused by the mechanism explained above. It was revealed that the significant drop in $F_{b 1}$ and $F_{b 2}$ in the later phase of isovolumic relaxation at AT $=207$ [ms] (Fig. 9(a)) occurred because $L_{1}$ and $L_{2}$ were sufficiently extended to generate effective $F_{p 1}$ and $F_{p 2}$, which were not shown but was clear from exaggerated increases in $L_{1}$ and $L_{2}$ (Fig. 9(b)). Since dissecting cellular parameters from living human or animal tissue is almost impossible, these results may suggest fundamental characteristics of constituting cells through understanding of a mathematical contraction model.

Since we could not find any experimental data corresponding to these simulation results, the results are theoretical predictions that are derived from the physiological characteristics of cardiac cells and circulation system.

\subsection{Comparing simulation results with other reports}

In Table 4, we can see that max dp/dt decreases markedly from the physiological AT of 99 [ms] to the prolonged AT of 207 [ms], and ejection time was delayed accompanying the increase in AT. Decreased max dp/dt and delayed ejecting time in LBBB are known $[3,33,34]$, which may partly correspond to the simulation results. The physiological range of $\max \mathrm{dp} / \mathrm{dt}$ is around $0.85-$ $2.0[\mathrm{mmHg} / \mathrm{ms}]$ [35], but the value was $6.178[\mathrm{mmHg} / \mathrm{ms}]$ in our model. From the LV pressure time course shown in Fig. 5(a), the pressure rise before the ejection phase seems slightly high, which deviates from the clinical data. This may be due to the problem of reproducibility of cardiac contraction stress time course of the NL08 model. Thus, direct evaluation or comparison between the max dp/dt value obtained from our model and clinical data is not possible. However, since the effect of this difference on total hemodynamics is not overly large and the difference in the shape of the pressure rise between AT $=99$ [ms] data and AT $=207$ [ms] data is quite small, we consider that the relative difference still reflects basic characteristics of the phenomena. Takeshita et al. [3] reported the max $\mathrm{dp} / \mathrm{dt}$ difference between normal and LBBB conditions in a patient who showed a $1.00[\mathrm{mmHg} / \mathrm{ms}]$ to $0.48[\mathrm{mmHg} / \mathrm{ms}]$ drop. Their relative difference in $\max \mathrm{dp} / \mathrm{dt}$ be- 


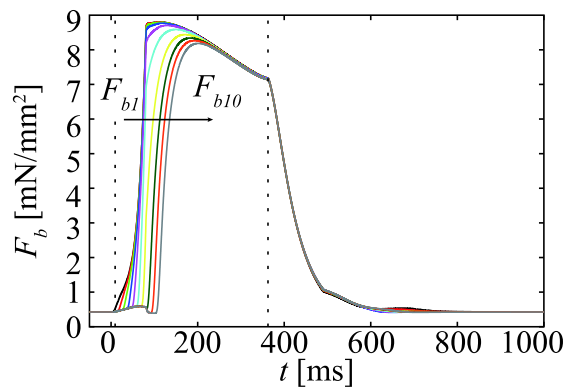

(a) $F_{b 1}-F_{b 10}$

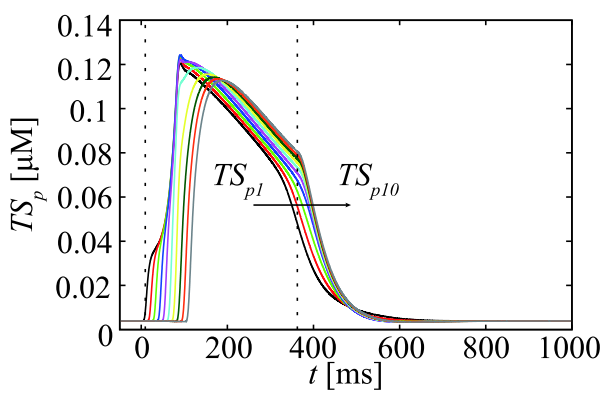

(c) $T S p_{1}-T S p_{10}$

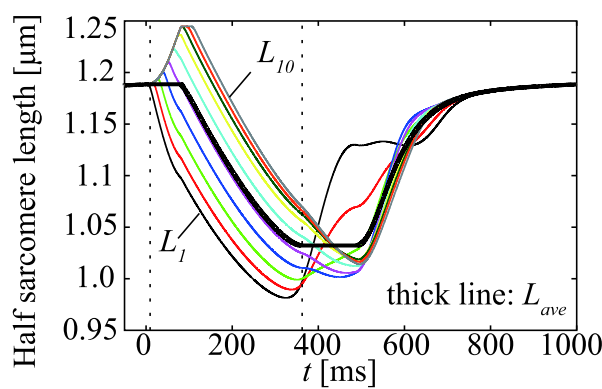

(b) $L_{1}-L_{10}$

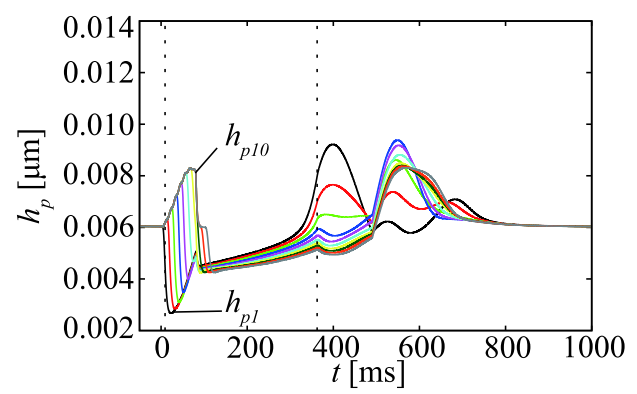

(d) $h_{p 1}-h_{p 10}$

Fig. 8 Time courses of $F_{b 1}-F_{b 10}, L_{1}-L_{10}$ and $L_{a v e}, T S_{p 1}-T S_{p 10}$, and $h_{p 1}-h_{p 10}(\mathrm{AT}=99$ [ms]). Cell 1 was activated at $t=0$ [ms]. The vertical dashed line on the left represents end-diastole, and the vertical dashed line on the right represents end-systole.

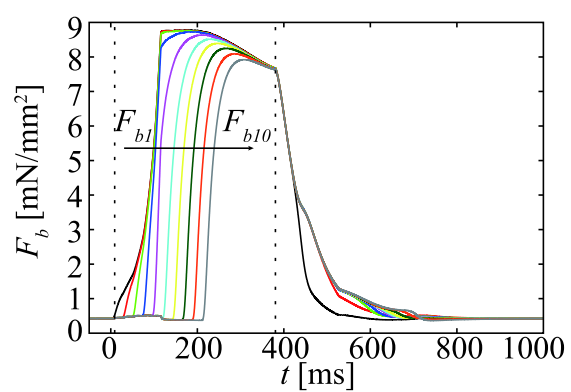

(a) $F_{b 1}-F_{b 10}$

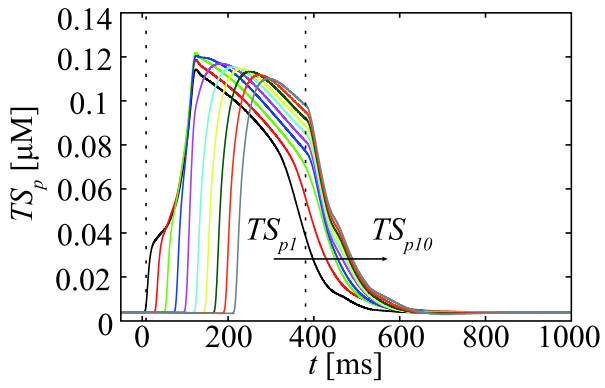

(c) $T S p_{1}-T S p_{10}$

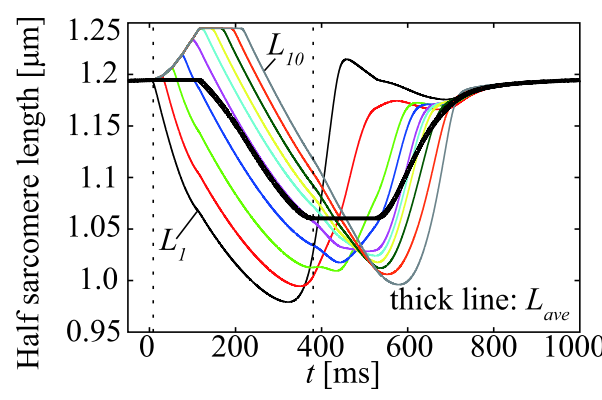

(b) $L_{1}-L_{10}$

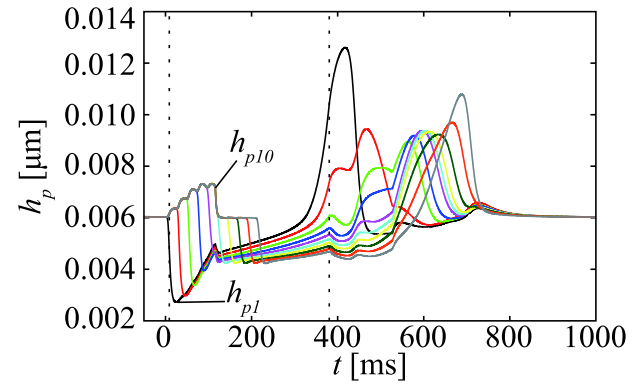

(d) $h_{p 1}-h_{p 10}$

Fig. 9 Time courses of $F_{b 1}-F_{b 10}, L_{1}-L_{10}$ and $L_{a v e}, T S_{p 1}-T S_{p 10}$, and $h_{p 1}-h_{p 10}$ (AT $=207$ [ms]). Cell 1 was activated at $t=0$ [ms]. The vertical dashed line on the left represents end-diastole, and the vertical dashed line on the right represents end-systole.

tween normal and LBBB conditions is close to our simulation results, suggesting that the model may reflect to some extent the effect of AT on cardiac pump function.

While max dp/dt decreased by $43.7 \%$, EF and SV decreased by only $6.00 \%$ and $2.10 \%$, respectively, when AT increased from
99 [ms] to 207 [ms]. Moreover, the PV loops (Fig. 5(c)) showed that the hemodynamics were preserved even if AT was prolonged to 207 [ms]. These results suggest that the parameters directly relating to cardiac output, such as EF and SV, may be robust to AT prolongation, while max $\mathrm{dp} / \mathrm{dt}$ is predisposed to decrease mark- 


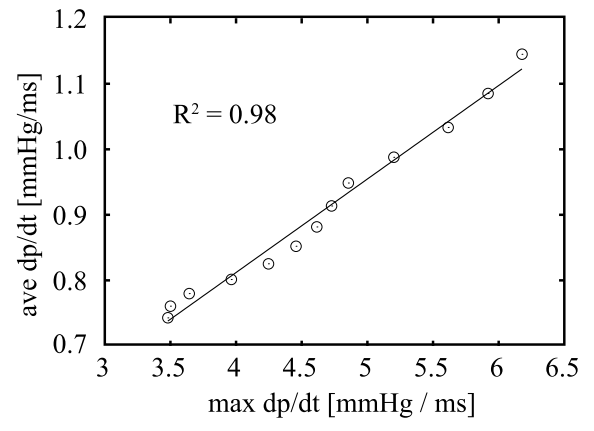

Fig. 10 ave dp/dt vs $\max d p / d t$.

edly with AT prolongation, which implies that blood circulation function may be robust to AT prolongation.

Lu et al. [5] reported that peak tissue contraction stresses were influenced by AT in the simulation under isometric condition, but the influence was small. Our study found a similar result that the decrease in peak $p_{l v}$ was not large, but also revealed that $\max \mathrm{dp} / \mathrm{dt}$ was markedly affected by AT in the hemodynamic simulation model.

In the research by Nelson et al. [36], measured data showed a strong correlation between QRS duration and max dp/dt. Since the duration of isovolumic contraction phase is the major determining factor for max dp/dt, we calculated average LV pressure rise (ave $\mathrm{dp} / \mathrm{dt}[\mathrm{mmHg} / \mathrm{ms}]$ ) in the isovolumic contraction phase from the isovolumic contraction phase duration and $p_{l v}$ difference for AT $=99$ [ms] to 207 [ms] data. The relationship between max $\mathrm{dp} / \mathrm{dt}$ and ave dp/dt is shown in Fig. 10. The results show a highly linear relationship between them $\left(R^{2}=0.98\right)$. Duration of the isovolumic contraction phase increased by $49.5 \%$ when AT increased from 99 [ms] to 207 [ms], while $p_{l v}$ difference between end-diastole and ejection point decreased by $3.02 \%$. This indicates that almost $94.2 \%$ of the decrease in $\max \mathrm{dp} / \mathrm{dt}$ is due to prolongation of the duration of the isovolumic contraction phase.

From Table 4, SV and EF decreased when AT increased from 99 [ms] to 207 [ms]. If conditions are the same, SV reportedly shows a strong positive correlation with duration of the ejection phase [37]. Another report found strong negative correlations between QRS duration and ejection phase duration, and between QRS duration and EF for QRS durations longer than 120 [ms] [38]. Our simulation results are consistent with these reports.

Since this study is still in the preliminary stage, we did not consider AT and contraction in the right ventricle (RV) in the hemodynamic model used in our study. In other words, simulations were performed while excluding the effects of RV contraction and inter-ventricular asynchrony (inter VA). Differences therefore exist between our simulation results and experimental results using real hearts. We used QRS duration as the index of AT and evaluated influences of AT alteration on hemodynamic parameters. However, in real hearts, cardiac function can be changed by alteration of inter VA even if QRS duration is unchanged, as reported by Verbeek et al. [39], representing a situation that cannot be simulated by our model. Comparing our results with their report, although SV decreased only a little by AT prolongation in our results, SV decreased markedly under prolonged QRS duration with increased inter VA in their results. The cause of this difference may be the influence of synchrony between LV and
RV. On the other hand, other data from their report suggested that $\max \mathrm{dp} / \mathrm{dt}$ increased when intra-ventricular asynchrony was large, corresponding to the significant increase in $\max \mathrm{dp} / \mathrm{dt}$ at longer AT in our study. In addition, they also reported no significant differences in end-diastolic pressure and end-diastolic volume between normal and prolonged QRS durations. In our simulation, no significant differences in EDPVR were seen even when AT increased from 99 [ms] to 207 [ms], which may correspond to their experimental results.

In the clinical data and conscious-condition animal experiments, preload and afterload conditions are controlled by the autonomic nervous system, which may affect hemodynamic parameters. In our simulation model, preload and afterload conditions are controlled manually, so direct comparison between experimental data and our simulation data might show deviations. However, since the changes in hemodynamic parameters are relatively small in terms of physiological preload and afterload conditions, the results can be considered to have meaningful differences.

\section{Conclusion}

In this research, we aimed to analyze the relationship between AT and hemodynamics using a human hemodynamic model by incorporating a cardiac tissue model into an LV geometric model within a circulation model, and also tried to analyze the underlying mechanism of the relationship. As a result of the simulations, we found that $E_{\max }$, EF and SV only decreased by $15.4 \%, 6.00 \%$ and $2.10 \%$, respectively, when physiological AT (99 [ms]) was prolonged to 207 [ms], while max dp/dt decreased markedly by $43.7 \%$. The cellular mechanisms underlying changes in half sarcomere length were analyzed individually in 10 cells. Our analysis showed that the 10 cells were excited asynchronously and changed their half sarcomere lengths individually to generate equivalent $F$ with different balance between $F_{b}$ and $F_{p}$. Thus, even though hemodynamic parameters did not change significantly, large differences in cell behaviors were identified.

In this research, AT was altered by changing constant excitation delays among cardiac cells $\left(\delta_{\text {delay }}\right)$ in the cardiac tissue model. As future work, we are interested in integrating a cardiac cell model that includes modern ion channel models and an excitation contraction coupling model. This kind of model should prove useful for evaluating the influence of gap junction current on contraction stress. We are also interested in integrating cardiac cell models that can evaluate energy consumption.

\section{Conflict of Interest}

We have no conflicts of interest relationship with any companies or commercial organizations based on the definitions of the Japanese Society for Medical and Biological Engineering.

\section{Acknowledgement}

This research was supported in part by Kakenhi Grant Number 22136004.

\section{References}

1. Das MK, Cheriparambil K, Bedi A, Kassotis J, Reddy CV, Makan M, Dunbar CC, Saul B: Prolonged QRS duration (QRS $\geqq 170 \mathrm{~ms}$ ) and left axis deviation in the presence of left bundle branch block: A marker of poor left ventricular systolic function? Am Heart J. 142(5), pp. 756-759, 2001 
2. Grines CL, Bashore TM, Boudoulas H, Olson S, Shafer P, Wooley $\mathrm{C}$ : Functional abnormalities in isolated left bundle branch block. The effect of interventricular asynchrony. Circulation. 79(4), pp. 845-853, 1989

3. Takeshita A, Basta LL, Kioschos JM: Effect of intermittent left bundle branch block on left ventricular performance. Am J Med. 56(2), pp. 251-255, 1974

4. Murkofsky RL, Dangas G, Diamond JA, Mehta D, Schaffer A, Ambrose JA: A prolonged QRS duration on surface electrocardiogram is a specific indicator of left ventricular dysfunction. J Am Coll Cardiol. 32(2), pp. 476-482, 1998

5. Lu J, Nishi T, Ashihara T, Schneider N, Amano A, Matsuda T, Kotera H: The Influence of Activation Time on the Contraction Force of Myocardial Tissue: a Simulation Study. Biomed Eng. 44(1), pp. 170-176, 2006

6. Heldt T, Shim EB, Kamm RD, Mark RG: Computational modeling of cardiovascular response to orthostatic stress. J Appl Physiol. 92(3), pp. 1239-1254, 2002

7. Thomas F, Moriarty: The law of Laplace. Its limitations as a relation for diastolic pressure, volume, or wall stress of the left ventricle. Circ Res. 46(3), pp. 321-331, 1980

8. Corsi C, Veronesi F, Lamberti C, Bardo DME, Jamison EB, Lang RM, Mor-Avi V: Automated frame-by-frame endocardial border detection from cardiac magnetic resonance images for quantitative assessment of left ventricular function: validation and clinical feasibility. J Magn Reson Im. 29(3), pp. 560-568, 2009

9. Sutton MG, Tajik AJ, Gibson DG, Brown DJ, Seward JB, Guiliani ER: Echocardiographic assessment of left ventricular filling and septal and posterior wall dynamics in idiopathic hypertrophic subaortic stenosis. Circulation. 57(3), pp. 512-520, 2009

10. Rodriguez EK, Hunter WC, Royce MJ, Leppo MK, Douglas AS: A method to reconstruct myocardial sarcomere lengths and orientations at transmural sites in beating canine hearts. Am J Physiol Heart Circ Physiol. 263(1), pp. 293-306, 1992

11. Sabbah HN, Stein PD: Pressure-diameter relations during early diastole in dogs. Incompatibility with the concept of passive left ventricular filling. Circ Res. 48(3), pp. 357-365, 1981

12. Yun KL, Niczyporuk MA, Daughters GT, Ingeks NB, Stinson EB, Alderman EL, Hansen DE, Miller DC: Alterations in left ventricular diastolic twist mechanics during acute human cardiac allograft rejection. Circulation. 83(3), pp. 962-973, 1991

13. Gibson DG, Traill TA, Brown DJ: Changes in left ventricular free wall thickness in patients with ischaemic heart disease. Br Heart J. 39(12), pp. 1312-1318, 1977

14. Gerstenblith G, Ksen JF, Yin FC, Fortuin NJ, Lakatta EG, Weisfeldt ML: Echocardiographic assessment of a normal adult aging population. Circulation. 56(2), pp. 273-278, 1977

15. Hunter PJ, McCulloch AD, ter Keurs HE: Modelling the mechanical properties of cardiac muscle. Prog Biophys Mol Biol. 69(2), pp. 289-331, 1998

16. Kerckhoffs RC, Bovendeerd PH, Kotte JC, Prinzen FW, Smits K, Arts T: Homogeneity of cardiac contraction despite physiological asynchrony of depolarization: a model study. Ann Biomed Eng. 31(5), pp. 536-547, 2003

17. Rice JJ, Winslow RL, Hunter WC: Comparison of putative cooperative mechanisms in cardiac muscle: length dependence and dynamic responses. Am J Physiol Heart Circ Physiol. 276(5), pp. $1734-1754,1999$

18. Rice JJ, Wang F, Bers DM, de Tombe PP: Approximate model of cooperative activation and crossbridge cycling in cardiac muscle using ordinary differential equations. Biophys J. 95(5), pp. 2368 2390, 2008
19. Land S, Niederer SA, Aronsen JM, Espe EKS, Zhang L, et al.: An analysis of deformation-dependent electromechanical coupling in the mouse heart. J Physiol. 590(18), pp. 4553-4569, 2012

20. Negroni JA, Lascano EC: Simulation of steady state and transient cardiac muscle response experiments with a Huxley-based contraction model. J Mol Cell Cardiol. 45(2), pp. 300-312, 2008.

21. Klotz S, Hay I, Zhang G, Maurer M, Wang J, Burkoff D: Development of heart failure in chronic hypertensive Dahl rats focus on heart failure with preserved ejection fraction. Hypertension. 47(5), pp. 901-911, 2006

22. Corin WJ, Murakami T, Monrad ES, Hess OM, Krayenbuehl HP: Left ventricular passive diastolic properties in chronic mitral regurgitation. Circulation. 83(3), pp. 797-807, 1991

23. de Tombe PP, Ter Keurs HE: An internal viscous element limits unloaded velocity of sarcomere shortening in rat myocardium. J Physiol. 454(1), pp. 619-642, 1992

24. Granzier HL, Irving TC: Passive tension in cardiac muscle: contribution of collagen, titin, microtubules, and intermediate filaments. Biophys J. 68(3), pp. 1027-1044, 1995

25. Shim EB, Amano A, Takahata T, Shimayoshi T, Noma A: The cross-bridge dynamics during ventricular contraction predicted by coupling the cardiac cell model with a circulation model. J Physiol Sci. 57(5), pp. 275-285, 2007

26. Landesberg A, Sideman S: Mechanical regulation of cardiac muscle by coupling calcium kinetics with cross-bridge cycling: a dynamic model. Am J Physiol Heart Circ Physiol. 267(2), pp. 779-795, 1994

27. Utaki H, Taniguchi K, Konishi H, Himeno Y, Amano A: A Method for Determining Scale Parameters in a Hemodynamic model incorporating Cardiac Cellular Contraction model. Adv Biomed Eng. 2015, (in press).

28. Barold SS, Mugica J: The Fifth Decade of Cardiac Pacing, 1st ed. Wiley-Blackwell, 2003.

29. Sarai N, Matsuoka S, Noma A: simBio: a Java package for the development of detailed cell models. Prog Biophys Mol Biol. 90(1), pp. 360-377, 2006

30. Hayward CS, Kalnins WV, Kelly RP: Gender-related differences in left ventricular chamber function. Cardiovasc Res. 49(2), pp. 340-350, 2001

31. Bermejo J, Yotti R, Perez del Villar C, del Alamo JC, Rodriguez-Perez D, Martinez-Legazpi P, Benito Y, Antoranz JC, Desco MM, Gonzalez-Mansilla A, Barrio A, Elizaga J, Fernandez-Aviles F: Diastolic chamber properties of the left ventricle assessed by global fitting of pressure-volume data: improving the gold standard of diastolic function. J App Physiol. 115(4), pp. 556-568, 2013

32. Hoole SP, White PA, Read PA, Heck PM, West NE, O'Sullivan M, Dutka DP: Coronary collaterals provide a constant scaffold effect on the left ventricle and limit ischemic left ventricular dysfunction in humans. J App Physiol. 112(8), pp. 1403-1409, 2012

33. Wolferth CC, Margolies A: Asynchronism in contraction of the ventricles in the so-called common type of bundle-branch block: its bearing on the determination of the side of the significant lesion and on the mechanism of split first and second heart sounds. Am Heart J. 10(4), pp. 425-452, 1935

34. Bourassa MG, Boiteau GM, Allenstein BJ: Hemodynamic studies during intermittent left bundle branch block. Am J Cardiol. 10(6), pp. 792-799, 1964

35. Sharman JE, Qasem AM, Hanekom L, Gill DS, Lim R, Marwick TH: Radial pressure waveform $\mathrm{dP} / \mathrm{dt}$ max is a poor indicator of left ventricular systolic function. Eur J Clin Invest. 37(4), pp. 276-281, 2007 
36. Nelson GS, Curry CW, Wyman BT, Kramer A, Declerck J, Talbot M, Douglas MR, Berger RD, McBeigh ER, Kass DA: Predictors of systolic augmentation from left ventricular preexcitation in patients with dilated cardiomyopathy and intraventricular conduction delay. Circulation. 101(23), pp. 2703-2709, 2000

37. Weissler AM, Harris WS, Schoenfeld CD: Systolic time intervals in heart failure in man. Circulation. 37(2), pp. 149-159, 1968

38. Shamim W, Yousufuddin M, Cicoria M, Gibson DG, Coats AJS, Henein MY: Incremental changes in QRS duration in serial ECGs over time identify high risk elderly patients with heart failure. Heart. 88(1), pp. 47-51, 2002

39. Verbeek XA, Vernooy K, Peschar M, Cornelussen RN, Prinzen FW: Intra-ventricular resynchronization for optimal left ventricular function during pacing in experimental left bundle branch block. J Am Coll Cardiol. 42(3), pp. 558-567, 2003

\section{Kosuke TANiguchI}

Kosuke TANIGUCHI received the bachelor's degree from Ritsumeikan University in 2015. He has been a master's student in Department of Life Sciences at Ritsumeikan University since 2015. His current research interests is biological simulation.

\section{Hiromasa UTAKI}

Hiromasa UTAKI received the bachelor's degree from Ritsumeikan University in 2015. He has been a master's student in Department of Life Sciences at Ritsumeikan University since 2015. His current research interests is biological simulation. He is a member of the Physiological Society of Japan.

\section{Daichi YамAMOTO}

Daichi ҮАмамото received the master's degree in biology from Ritsumeikan University in 2014. He has been working at Balto Software Co., Ltd. since 2014.

\section{Yukiko Himeno}

Yukiko Himeno received her Ph.D. degree from Kyoto University in 2008. She worked for Kyoto University Hospital as a postdoc from 2008 to 2012 and for the Japan Society for the Promotion of Science as a research fellowship from 2012 to 2015. She has been working at Ritsumeikan Uni-

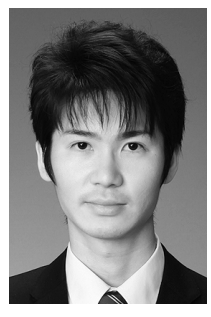
versity as an assistant professor since 2015 . Her current research interests are biological simulation and cardiovascular physiology. She is a member of the Physiological Society of Japan.

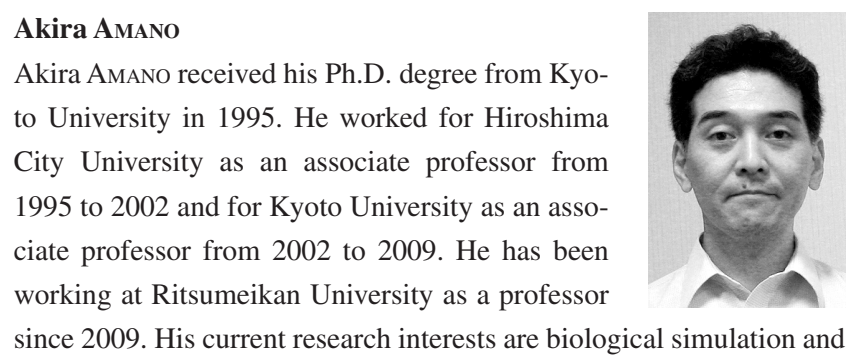
MRI. He is a member of JSMBE, IEEE-EMBS, IEEE-CS and IEICE. 